\title{
BRIEF
}

\section{Novel Use of LMS Data to Predict Online Learning Success in A Pharmacy Capstone Course}

\author{
Kelsey Buckley, PharmD, Kathleen Fairman, MA, PhD, Elizabeth Pogge, PharmD, Erin Raney, PharmD \\ Midwestern University, College of Pharmacy, Glendale, Arizona

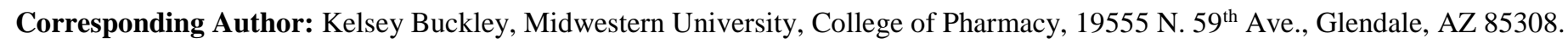 \\ Tel: 623-572-3539. Email: kbuckley@ midwestern.edu
}

Submitted February 15, 2021; accepted July 23, 2021; ePublished August 2021

Objective. Learning management system (LMS) data from online classes may provide opportunities to identify students at risk of failure. Previous LMS studies have not addressed the possibility of change in student engagement over time. The purpose of this study was to apply a novel statistical technique, group-based trajectory modeling (GBTM), to LMS data for an online course to identify predictors of successful course completion.

Methods. Exploratory GBTM assessed the association of LMS activity (total activity time, dates of activity, and pages viewed) and attendance at virtual synchronous learning sessions with examination performance in a capstone diseasemanagement course delivered in the final didactic quarter of a three-year Doctor of Pharmacy program. Groups were assigned based on trajectories of weekly page-view counts using structural-equation modeling.

Results. GBTM identified three page-view engagement groups (median total page views, $\mathrm{n})$ : Group 1, high $(1,818, \mathrm{n}=24)$ : Group 2, moderate $(1,029, \mathrm{n}=74)$, and Group 3, low (441 views, $\mathrm{n}=35)$. Group assignment alone was somewhat associated with final grade. Stratification based on consistent virtual synchronous learning session attendance improved predictive accuracy; for example, a top (A or A-) grade was earned by $49.0 \%$ and $24.0 \%$, respectively, of Group 2 students with and without consistent synchronous engagement.

Conclusion. Application of GBTM to LMS data, including information about synchronous engagement, could provide early warning signs of potential for course failure, helping instructors to target interventions to at-risk students. The technique should be further tested with alternative LMS data and early in didactics, before patterns of engagement are established.

Keywords: student pharmacists, pharmacy education, virtual learning, active learning

\section{INTRODUCTION}

Colleges of pharmacy have moved incrementally in the past two decades toward increasing use of digital technologies including online instruction, a trend that accelerated sharply in 2020 and may continue in the future $\cdot{ }^{1-7}$ Key principles of effective online teaching, including instructor presence and learner-centered instruction, suggest a need for timely support of academically at-risk students to promote student self-efficacy and prevent failure. ${ }^{8,9}$ However, identification of at-risk students in online environments can be challenging because of physical separation and lack of face-to-face interaction. ${ }^{8}$

Responding to this need, a small body of work has examined use of learning management system (LMS) data to measure the association of online engagement with student success or identify warning signs of disengagement that may signal a need for instructor intervention. ${ }^{10-14}$ Few of these studies have been conducted in $100 \%$ online-delivered courses, where LMS data provide a relatively complete measure of student activity. ${ }^{10,13}$ These studies have employed various measures of engagement (eg,, total time online; number of discussion posts, mouse clicks, screen, or video views; or chosen activities, such as text-reading versus video-watching), and diverse statistical methods (eg,, correlation analysis, decision-tree modeling, regression analysis, and descriptive statistics). ${ }^{10-14}$

An important gap in this literature is lack of measurement of change in student engagement over time. Except for one study that assessed test-test reliability of mouse click counts, most studies assessed the effects of totals, such as total screen views, summed over the entire course. ${ }^{13}$ This approach may mask important differences in patterns of engagement. For example, a student at the $50^{\text {th }}$ percentile for total screen views may have viewed $100 \%$ of screens in the first half of the class and $0 \%$ thereafter or $50 \%$ of screens throughout. In that respect, LMS research faces a problem similar to that described in literature on medication adherence, when investigators noted that standard measures, such as percentage of days covered, failed to address the possibility of dynamic change in adherence behaviors, such as gradual versus sudden declines or increases in chronic medication use. ${ }^{15,16}$ 
Health services researchers responded to this problem using group-based trajectory modeling (GBTM), a statistical technique that originated in the behavioral sciences as a way to characterize life courses of chronic criminal offenders. ${ }^{15-17}$ The approach is built on an understanding of human development as a dynamic process that may change over time, making it desirable to study patterns of behavioral change. ${ }^{17}$ GBTM is a structural equation modeling technique in which cases are classified into groups based on trajectories, which are patterns of behaviors measured at regular time intervals. ${ }^{18-20}$ For example, GBTM studies of medication adherence often identify groups of consistent adherers, consistent nonadherers, initial nonadherers followed by increased adherence, and declining adherers. ${ }^{15}$

To meet the need for a dynamic measure of student engagement, we applied GBTM to LMS data from a Disease State Management (DSM) course offered during the final didactic quarter prior to advanced pharmacy practice experiences in a three-year Doctor of Pharmacy program that enrolls approximately 140 students annually. DSM is a 4.5credit capstone course in which case-based lectures reinforce and apply previous didactic coursework on disease states commonly seen in ambulatory-care practice. Although typically delivered in person, the class was offered fully online using recorded lectures in 2020. To augment these lectures, a virtual synchronous component was offered throughout the quarter, in which students could participate in 11 live discussions with a course instructor. Attendance was taken at both the start and end of each virtual session to verify complete participation. All course material was recorded and posted to the online LMS for student viewing. The purpose of this exploratory study was to identify predictors of success, measured as course grade, using LMS data.

\section{METHODS}

Total course pages accessed for each of 10 weeks of the class were summed across page view counts captured daily by the LMS and used in GBTM modeling. (See footnotes to the first Results figure for detailed technical information about model construction.) Group assignments were based on a probability threshold of 0.70 , meaning the model predicted a $\geq 70 \%$ probability of membership in that group based on the student's trajectory of page views over time.

Group-assignment construct validity was tested by plotting weekly mean page views, stratified by group, and by characterizing central tendency and dispersion using boxplots and coefficients of variation (COV), a ratio of standard deviation to mean typically used to assess within-group variability in GBTM and other applications. ${ }^{21,22}$ Within-group variability was tested because a successful classification process would be expected to reduce heterogeneity, that is, to make the groups more homogeneous than the sample as a whole.

Additionally, criterion validity was assessed using group membership to predict course grade, with significance of the association tested with the Fisher-Freeman-Halton exact test. When the criterion validity analysis produced a weak association, we stratified each group with a binary indicator of attendance at $\geq 10$ of 11 virtual synchronous learning sessions, intended to represent consistent, better-quality engagement. This post hoc stratification was based on the known association of active engagement with learning. ${ }^{23}$

\section{RESULTS}

GBTM stratified students into three page-view groups: Group 1 (high engagement; $n=24$ ); Group 2 (moderate engagement; $n=74$ ); and Group 3 (low engagement; $n=35$; Figure 1, top panel). Mean probabilities of membership in the assigned groups were 97\%-98\%. Five students did not meet the 70\% threshold in any group and could not be classified because their weekly page counts fluctuated widely, with no discernible pattern (Figure 1, bottom panel). Plots and COV analysis showed a considerable decline in group heterogeneity and clear between-group distinctions in patterns of page views over time (Figure 1; Figure 2). COVs for total page views were reduced by modeling from 0.60 for the sample overall to 0.24-0.30 for the individual groups, indicating that application of the GBTM technique substantially reduced heterogeneity, measured as standardized within-group variation. Group 1 students viewed considerably more pages than did students in the other two groups, with median total LMS page views of 1,818, 1,029, and 441 for Groups 1, 2, and 3, respectively, over the 10 -week course.

Despite this difference, the association of model-assigned group with course grade was modest and nonsignificant ( $p=.282)$. The association became stronger, albeit still statistically nonsignificant at a typical alpha threshold of 0.05 $(p=.093)$, after stratification for attendance at virtual synchronous learning sessions (Table 1). An additional post hoc analysis of total LMS hours spent over the 10 weeks further supported the stratification, indicating a negative association between total page views and total LMS hours (median total hours of 59, 75, and 81 for Groups 1, 2, and 3, respectively). Thus, the more pages viewed, the less total time spent, suggesting that modeling based on page view counts alone was inadequate to capture engagement.

\section{DISCUSSION}


This exploratory analysis of LMS data indicated that students could be classified accurately into groups based on page view counts using GBTM. Page view counts alone, the only engagement metric available at the regular intervals required by GBTM, did not successfully predict student achievement until stratification by attendance at virtual synchronous learning sessions was performed. In this respect, we found an inconsistency between predictors of student performance and an assumption of GBTM, that cases do not vary within groups. ${ }^{19}$ This need to supplement the insights gained from GBTM with an additional measure of student engagement, virtual synchronous learning session attendance, likely reflects the effects of two factors.

The first is that unlike medication adherence research using GBTM, our findings suggested relatively stable patterns of student engagement. ${ }^{15}$ A possible explanation for this finding is that underlying predisposition to success prompts meaningful engagement. One path model analysis suggested that student grade on a prerequisite course was the strongest predictor of performance in a higher-level anatomy class, with LMS engagement measured throughout the anatomy class acting as a mediating factor. ${ }^{11}$ This interpretation could explain why consistent, live interaction with instructors, a stable trait measured throughout the quarter, had value as a predictor of success beyond information provided by GBTM. Although that finding does indicate less than the anticipated value in using GBTM for this class, it should be noted that during the final didactic quarter of the curriculum, students' patterns of engagement and predisposition for success were probably well established. Whether this finding would be similar in Doctor of Pharmacy coursework delivered earlier in the curriculum or for different disciplines is unknown.

The second factor is the limitation of data available in the LMS. Minutes of online time might have provided a better weekly measure of active learning time than page view counts did. The post hoc finding of a negative association between total page views and total online time supports this interpretation by suggesting that some students with many page views clicked quickly through the pages, likely without reading them carefully. Our LMS made minutes of online time visible to instructors only for the entire course, rather than weekly as needed for GBTM. This constraint, along with the wide variety of LMS metrics reported in the literature, suggest a need to use LMS data that represents active learning, such as engagement in interactive tasks or counts of discussion postings. ${ }^{10,11,14}$ Instructors interested in using this technique could request necessary system modifications from the LMS developer to obtain regular access to additional metrics already being collected.

To the authors' knowledge, this is the first time GBTM has been used to correlate LMS data with student success. ${ }^{15,16}$ Despite the limitations encountered in application of GBTM to this course, our success in classifying distinctive student groups with GBTM suggests the possibility of using this approach not only in pharmacy schools, but also in other higher learning institutions, to help identify at-risk students for early intervention to improve success rates. With the shift to more online courses, additional methods to quantify student engagement will continue to be important, despite LMS limitations. ${ }^{10-14}$

Unlike blended courses, where in-person instruction makes LMS data incomplete, the abrupt shift to $100 \%$ online course delivery in the coronavirus (COVID-19) pandemic afforded instructors expanded opportunities to evaluate predictors of success. The finding of a potential association between course grade and virtual synchronous session attendance presented such an opportunity and has implications apart from use of GBTM. This finding may be explained by the unique benefits offered by synchronous and asynchronous teaching methods. While asynchronous instruction offers the student scheduling convenience, the opportunity to work at an independent pace, and time to process information, synchronous instruction can increase motivation due to personal connection with the instructor and peer students. ${ }^{24}$ Additionally, compared with recorded lectures, synchronous sessions were more similar to the pre-pandemic learning environment, as our students were accustomed to in-person course delivery. Nonetheless, this research adds to a body of work suggesting better course performance when students engage with peers or the instructor, either online or in person. ${ }^{8,10,23,25}$ Although this principle is seemingly obvious from the perspective of most faculty, our findings suggest that students working within asynchronous and anonymized didactic formats may be unaware of the need to engage with their instructors.

Several limitations should be noted. First, this evaluation represents the findings of one course offering at one program and is thus limited by a small sample size and limited application outside this context. Second, the context of the movement of the course to $100 \%$ online administration was the global COVID-19 pandemic, when students may have experienced additional family obligations and stressors that could have affected their course engagement or performance. Studies done in different contexts might have produced different results. Third, students may have interacted to varying degrees with the course material outside of the LMS, such as downloading handouts to view offline, making study materials, or other active-learning activities. Neither offline engagement nor the possibility of students viewing the material on a peer's LMS could be measured in this research and remains an area for future inquiry. Lastly, while attendance was taken twice at each virtual session, we did not account for the variable level of student engagement that could have occurred at these sessions. 


\section{CONCLUSION}

The use of GBTM provided a model for characterizing predictors of student success in a course transitioned to virtual delivery. Early and consistent engagement with course materials in the LMS and participation in virtual synchronous learning sessions may be associated with higher course grades. This information will be used to provide constructive recommendations for students desiring positive course outcomes. To address limitations in use of GBTM in the present study, the technique should be further tested with alternative LMS data and early in didactics, before patterns of engagement are established.

\section{REFERENCES}

1. Monaghan MS, Cain JJ, Malone PM, et al. Educational technology use among US colleges and schools of pharmacy. Am J Pharm Educ. 2011;75(5):Article 87.

2. Blouin RA, Riffee WH, Robinson ET, et al. Roles of innovation in education delivery. Am J Pharm Educ. 2009;73(8):Article 154.

3. Salter SD, Karia A, Sanfilippo FM, Clifford RM. Effectiveness of E-learning in pharmacy education. Am J Pharm Educ. 2014;78(4):Article 83.

4. Romanelli F, Rhoney DH, Black EP, Conway J, Kennedy DR. Pharmacy education crosses the rubicon. Am J Pharm Educ. 2020;84(6): Article 8131.

5. Kawaguchi-Suzuki M, Nagai N, Akonoghrere RO, Desborough JA. COVID-19 pandemic challenges and lessons learned by pharmacy educators around the globe. Am J Pharm Educ. 2020;84(6):Article 8197.

6. Lyons KM, Christopoulos A, Brock TP. Sustainable pharmacy education in the time of COVID-19. Am J Pharm Educ. 2020;84(6):Article 8088.

7. Schlesselman LS. Perspective from a teaching and learning center during emergency remote teaching. Am J Pharm Educ. 2020;84(6):Article 8142.

8. Stavredes T. Effective Online Teaching: Foundations and Strategies for Student Success. San Francisco CA: John Wiley \& Sons, Inc.; 2011.

9. Jin J, Bridges SM. Educational technologies in problem-based learning in health sciences education: a systematic review. J Med Internet Res. 2014;16(12):e251.

10. Ammenwerth E, Hackl WO, Dornauer V, et al. Impact of students' presence and course participation on learning outcomes in co-operative online-based courses. Stud Health Technol Inform. 2019;262:87-90.

11. Green RA, Whitburn LY, Zacharias A, Byrne G, Hughes DL. The relationship between student engagement with online content and achievement in a blended learning anatomy course. Anat Sci Educ. 2018;11:471-477.

12. Saqr M, Fors U, Tedre M. How learning analytics can early predict under-achieving students in a blended medical education course. Med Teach. 2017;39(7):757-767.

13. Tellakat M, Boyd RL, Pennebaker JW. How do online learners study? The psychometrics of students' clicking patterns in online courses. PLos One. 2019;14(3):e0213863.

14. White LJ, McGowan HW, McDonald AC. The effect of content delivery style on student performance in anatomy. Anat Sci Educ. 2019;12:43-51.

15. Alhazami M, Pontinha VM, Patterson JA, Holdford DA. Medication adherence trajectories: a systematic literature review. J Manag Care Spec Pharm. 2020;26(9):1138-1152.

16. Franklin JM, Shrank WH, Pakes J, et al. Group-based trajectory models: a new approach to classifying and predicting long-term medication adherence. Med Care. 2013;51(9):789-796.

17. Nagin DS, Odgers CL. Group-based trajectory modeling (nearly) two decades later. J Quant Criminol. 2010;26(4):445-453.

18. Nagin DS, Odgers CL. Group-based trajectory modeling in clinical research. Annu Rev Clin Psychol. 2010;6:109138.

19. Lore H, Nguefack N, Pagé MG, et al. Trajectory modelling techniques useful to epidemiological research: a comparative narrative review of approaches. Clin Epidemiol. 2020;12:1205-1222.

20. Hickson RP, Annis IE, Killeya-Jones LA, Fang G. Opening the black box of the group-based trajectory modeling process to analyze medication adherence patterns: an example using real-world statin adherence data. Pharmacoepidemiol Drug Saf. 2020;29(3):357-362.

21. Williams KY, O'Reilly CA. Demography and diversity in organizations: a review of 30 years of research. Res. Organ. Behav. 1998;20:77-140.

22. Lee CL, Sheu WH, Lee IT, et al. Trajectories of fasting plasma glucose variability and mortality in type 2 diabetes. Diabet. Metab. 2018;44(2):121-128. 
23. Ambrose SA, Bridges MW, DiPietro M, Lovett MC, Norman MK. How Learning Works: 7 Research-Based Principles for Smart Teaching. Jossey-Bass: 2010.

24. Hrastinski S.Asynchronous \& synchronous e-learning. https://er.educause.edu/articles/2008/11/asynchronousand-synchronous-elearning. Published November 17, 2008. Accessed February 11, 2021.

25. Saqr M, Fors U, Tedre M. How the study of online collaborative learning can guide teachers and predict students' performance in a medical course. BMC Medical Education. 2018;18:24. 
Table 1. Letter Grade Distribution by GBTM Groups, Before and After Stratification for Virtual Synchronous Learning Session Attendance

\begin{tabular}{|c|c|c|c|c|c|c|c|c|c|}
\hline & \multicolumn{3}{|c|}{$\begin{array}{l}\text { Group Assignment Only Based } \\
\text { on Engagement }^{\mathrm{a}, \mathrm{b}}\end{array}$} & \multicolumn{6}{|c|}{ Analysis Stratified by Number of Synchronous Sessions Attended ${ }^{a, b, c}$} \\
\hline & Group 1 & Group 2 & Group 3 & $\begin{array}{l}\text { Group 1, } \\
<10\end{array}$ & $\begin{array}{l}\text { Group 1, } \\
\geq 10\end{array}$ & $\begin{array}{l}\text { Group 2, } \\
<10\end{array}$ & $\begin{array}{l}\text { Group 2, } \\
\geq 10\end{array}$ & $\begin{array}{l}\text { Group 3, } \\
<10\end{array}$ & $\begin{array}{l}\text { Group 3, } \\
\geq 10\end{array}$ \\
\hline $\mathrm{N}$ of students & 24 & 74 & 35 & 8 & 16 & 25 & 49 & 23 & 12 \\
\hline Percentage grade distribution ${ }^{\mathrm{d}}$ & $\%$ & $\%$ & $\%$ & $\%$ & $\%$ & $\%$ & $\%$ & $\%$ & $\%$ \\
\hline $\mathrm{A}$ or $\mathrm{A}-$ & 29.2 & 40.5 & 22.9 & 12.5 & 37.5 & 24.0 & 49.0 & 13.0 & 41.7 \\
\hline $\mathrm{B}+$ or $\mathrm{B}$ & 37.5 & 35.1 & 34.3 & 50.0 & 31.3 & 40.0 & 32.7 & 43.5 & 16.7 \\
\hline $\mathrm{B}-, \mathrm{C}+$, or $\mathrm{C}$ & 33.3 & 24.3 & 42.9 & 37.5 & 31.3 & 36.0 & 18.4 & 43.5 & 41.7 \\
\hline
\end{tabular}

${ }^{\mathrm{a}} \mathrm{Groups}$ 1, 2, and 3, respectively, are High, Moderate, and Low Engagement based on weekly page-view counts.

${ }^{\mathrm{b}}$ Fisher-Freeman-Halton exact tests $p=.282$ for group only; $p=.093$ for stratified analysis.

${ }^{c} \geq 10$ means that the learner attended at least 10 of 11 available virtual synchronous sessions with course instructors.

${ }^{\mathrm{d} C}$ Course grading scale: A or A- $(100 \%-89 \%)$; B+ or B $(88.9 \%-82 \%)$; B-, C+, C $(81.9 \%-70 \%)$.

GBTM=group-based trajectory modeling 
Figure 1. Page View Counts by Week

Panel 1. Mean ${ }^{a}$ Page Views, by Week of Course, Stratified by Bayesian GBTM-Modeled Group ${ }^{\mathrm{b}}$

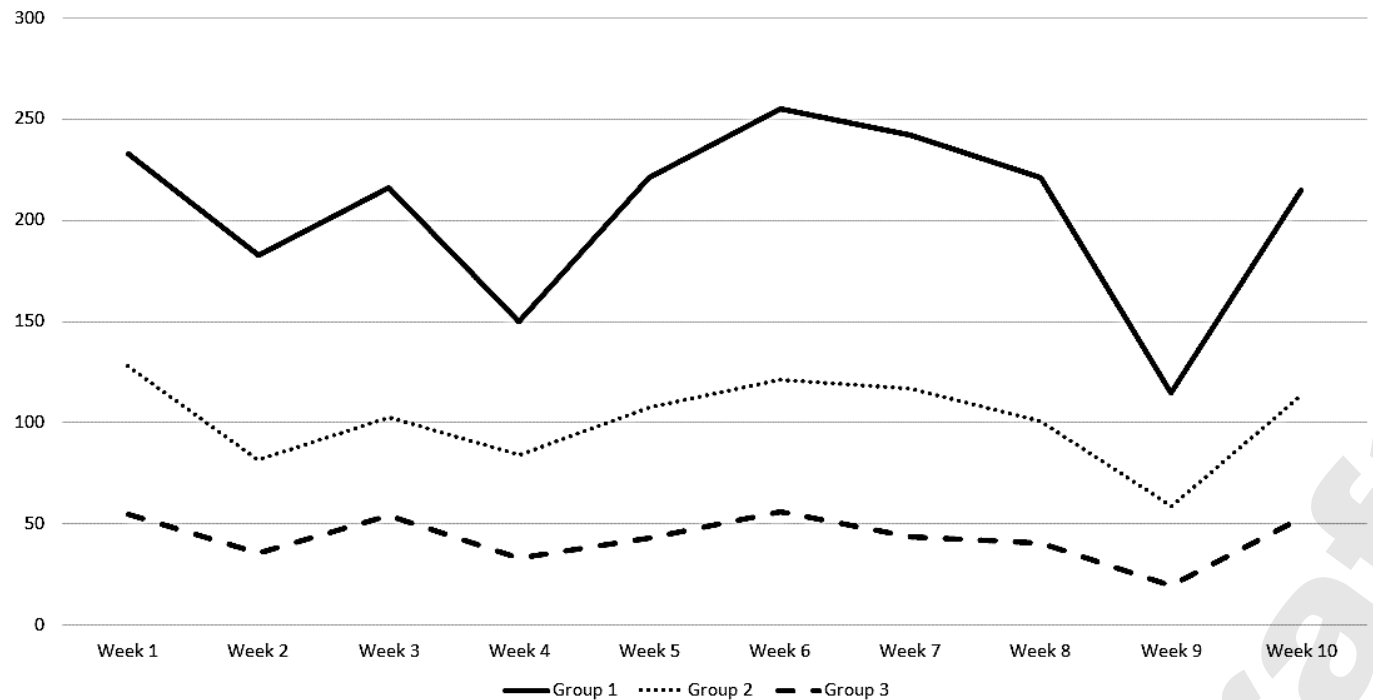

Panel 2. Total Page Views, by Week of Course, Five Students Not Classifiable Using Bayesian GBTM

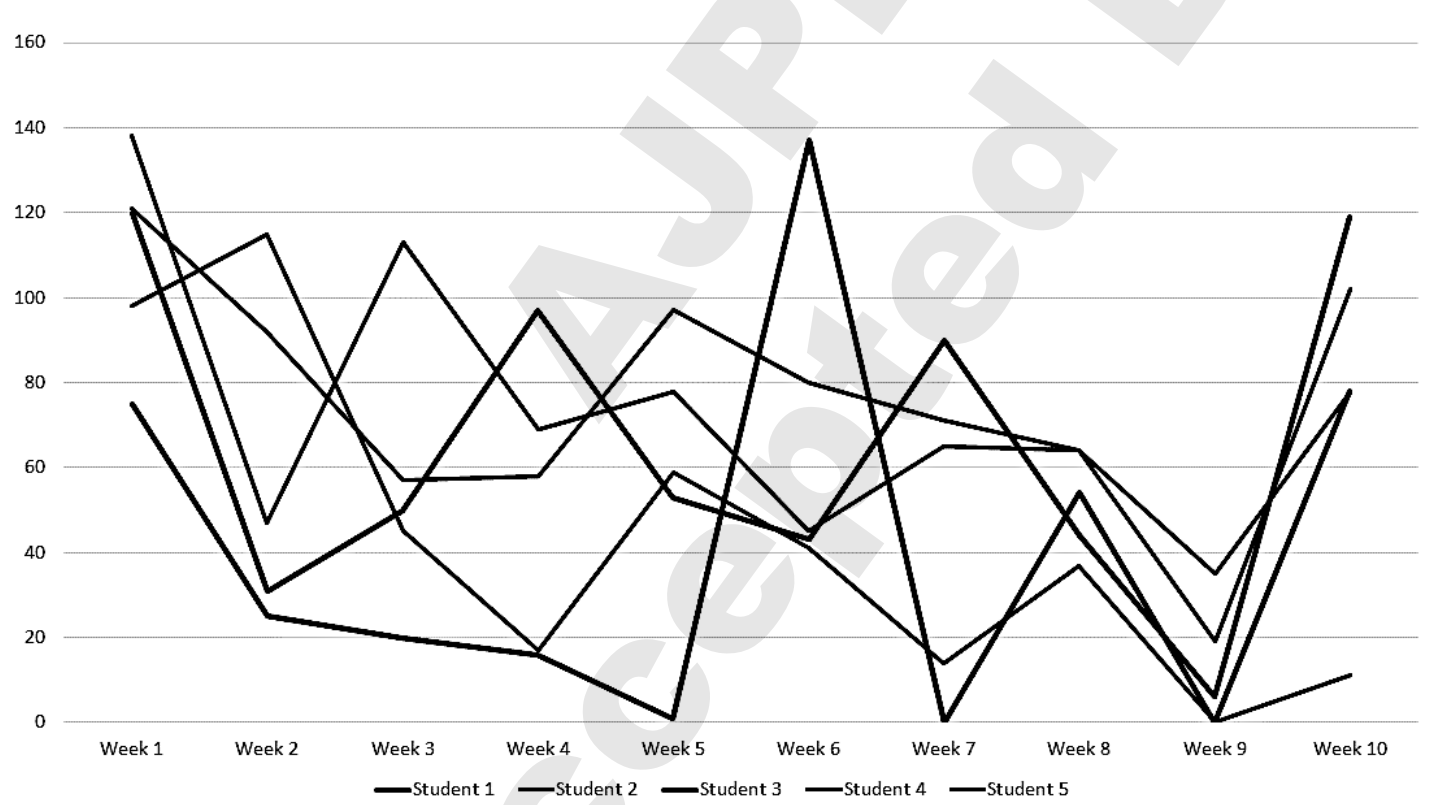

${ }^{a}$ Median page views, not shown in this graphic, were similar to the means shown. ${ }^{b}$ Groups 1,2 , and 3, respectively, are High, Moderate, and Low Engagement based on weekly page-view counts. GBTM=group-based trajectory modeling. GBTM-modeled group was identified using IBM SPSS AMOS (v 27.0; Armonk, NY) structural equation modeling with linear growth curve analysis over the 10 data points and Bayesian (ie,, accounting for prior probability) assignment of students to groups. Variance in slope and intercept were forced to zero (0) because GBTM assumes that the only factor explaining behavior (page views in this study) is group membership, an assumption necessary for computational efficiency and accuracy. ${ }^{19}$ Both a 3-group and 4-group solution were tested; only the 3-group solution produced a statistically reliable model. In addition to SPSS AMOS, which requires customized modeling to produce GBTM, software functions for this purpose include Proc Traj in SAS (Cary, NC), crimCV and lcmm in R (open-source software, https://www.r-project.org/), and traj in Stata (College Station, TX). ${ }^{19}$ 
Figure 2. Boxplots and Coefficient of Variation, Total Course Page Views

\section{Page Views}

Variation $^{\mathrm{a}}$

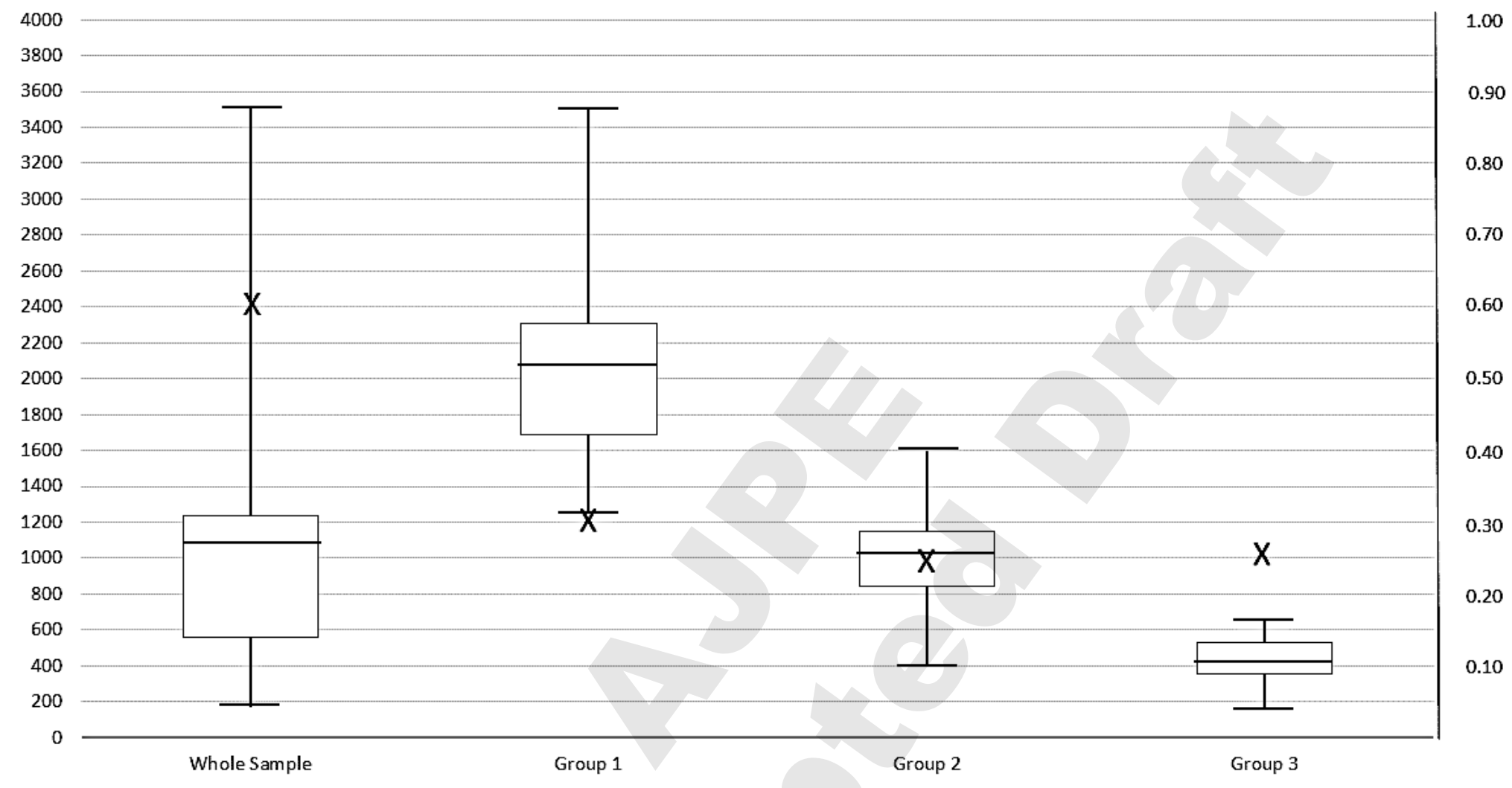

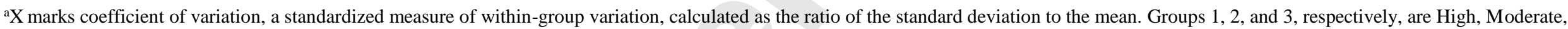
and Low Engagement based on weekly page-view counts. 